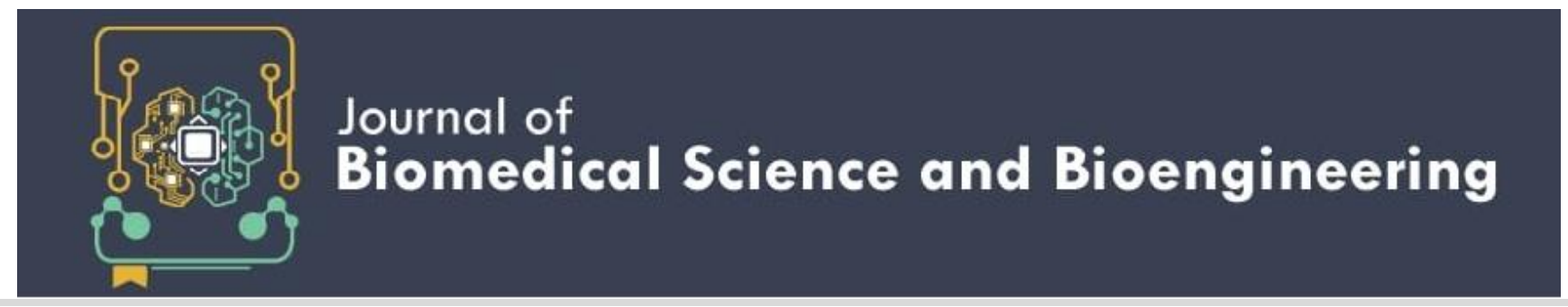

\title{
Effect of Using Coolant on the Formation of Microcracks, Burr and Delamination in Bone Drilling Process
}

\author{
Rusnaldy $^{1 *}$, Pratama Eka Putra Sijabat ${ }^{1}$, Paryanto $^{1}$ and Toni Prahasto ${ }^{1}$ \\ ${ }^{1}$ Department of Mechanical Engineering, Diponegoro University, Indonesia \\ *Corresponding author, email: rusnaldy@lecturer.undip.ac.id
}

\begin{abstract}
Direct approach for bone fracture treatment usually involves restoring the fractured parts to their initial position and immobilizing them with plates, screws and wires. This approach needs a bone surgery drilling to produce hole for screw insertion. But this drilling process causes mechanical damages, i.e microcracks, burr formation and delamination, that can reduce the stability of the fixation. One of the ways to minimize it is by using coolant. Moreover, it is noted that bone has anisotropic microstucture. The object of this study is to understand the effect of coolant on mechanical damages that occur in bone drilling and to understand the effect of microstructure difference on microcracks that occur in the drilled walls holes. Adult bovine bones and adult goat bones were used in this study as the specimens to represent differences in cortical bone microstructure. Five consecutive holes from the distal to the proximal in each specimen were generated using manual hand-drill (spindle speed $(\mathrm{n})=1000 \mathrm{rpm}$; drill bit $(\mathrm{d})=4 \mathrm{~mm}$ diameter) with the use of coolant as variation. The drilling holes then stained and observed using a microscope. As the result, it was found that the use of coolant can significantly reduce the drilling temperature. Microcracks, burr formation and delamination were found to be quite large in the drilling holes without coolant. However, there is no microcrack found in the drilling holes with coolant, there is only a small number of burr formation was found. In addition, it was found that the differences in bone microstructure affect the number and length of microcracks that occur in the wall of the hole. It can be concluded from this study that the application of coolant is very effective to reduce the drilling temperature and enhancing the quality of the hole generated by bone drilling and the higher the density of osteon in cortical bone, the easier the microcrack to initiate and propagate.
\end{abstract}

Keywords: Bone drilling, cortical bone, microstructure, osteon, microcracks, burr formation, delamination Article History: Received 6 July 2020; Accepted 8 April 2021; Available online: 10 April 2021 DOI: $10.14710 /$ jbiomes.2021.v1i1.17-26

\section{INTRODUCTION}

There are two basic approaches for bone fracture treatment; conventional approach and direct approach. In conventional approach, the immobilization of the fractured parts is done from outside using gypsum or wooden splint whereas direct approach is done from inside by attaching fixing plates using screws and wires to immobilize the fracture bone. Therefore, bone drilling is necessary to produce hole for screw insertion [1]. However, this mechanical action between the drill bit and bone can cause mechanical damages to the surroundings of the bone in form of microcracks, burr formation and delamination. These damages may cause the loosening of the fixation and may lead to failure of the implanted plate [1-4]. Therefore, bone fracture treatment is quite a technical assignment which must be handled in a very skillful way to produce a good quality of hole so that the joint can last long.

The bone drilling process is not fully understood because of its complex problems. Bone is a type of material that has complex properties [5]. The chip formation mechanism is very complex [6], the effect of microstructure of cortical bone and the heat generated during the drilling process is also very complex [7].

Several researchers have studied the effect of various factors on the quality of hole that generated by drilling of bone. Among the factors that affect the hole quality are the geometry of the drill bit, drilling speed, axial force, feed rate, pre-drilling, drill wear and usage of cooling fluids.
Studies examining hole quality in bone drilling can be reviewed in several fields. Some researchers have tried to improve the hole quality in bone drilling by studying the effect of machining parameters. Ndaruhadi et al. [8] studied the effect of spindle speed and feed rate on the surface topography of drilled holes walls in bovine bone drilling using two levels of cutting speed and feed rate as the input variables; which are $6 \mathrm{~m} / \mathrm{min}$ and $37 \mathrm{~m} / \mathrm{min}$ for cutting speed and $0.01 \mathrm{~mm} / \mathrm{rev}$ and $0.2 \mathrm{~mm} / \mathrm{rev}$ for feed rate. It is showed that feed rate has significant influence on surface roughness, while cutting speed does not result significant influence. Gupta et al. [9] studied the effect of feed rate and rotational speed using two different drilling technique; conventional surgical bone drilling (CSBD) and rotary ultrasonic bone drilling (RUBD). It is showed that the increase in rotational speed resulted in a decrease in the width and number of microcracks while the length and number of microcracks increased with the increasing of feed rate. Moreover, fewer and shorter microcracks were observed for RUBD as compared to holes drilled with CSBD. Alam and Qamar [10] studied the effect of spindle speed and feed rate on delamination in bovine bone drilling using conventional drilling (CD) and ultrasonic-assisted drilling (UAD). It is showed that drilling speed no significant effect on the level of delamination in both $\mathrm{CD}$ and UAD. Delamination was slightly increased with the increase of feed rate [11]. These results are also shown by Pandey and Panda [12] who concluded that the feed rate has highest influence on the 
percentage delamination while spindle speed has no significant influence.

In some studies, efforts have been made to analyze the effect of tool geometry on the mechanical damage that occurs in bone drilling. Pandey and Panda [12] studied the effect of drill bit geometry on delamination that occurs in drilled hole and shows that the increase in point angle, increases the mechanically damaged area around the drilled site (percentage delamination) whereas, the increase in helix angle decreases it. This phenomenon can be attributed to the fact that the increase in point angle increases the amount of initial shear deformation of bone during drilling. Moreover, the increase in helix angle facilitates easy removal of the chips during drilling, thus avoiding the additional force that occurs due to clogging of drill bit and therefore reduces the mechanical damage around the drilled hole. Sighn et al. [2] demonstrates the effect of tool geometry on mechanical damage in bone drilling using abrasive coated drill bit (AC), hollow tools (HP) and twist drill (TD). It is showed that twist drill gives a better surface finish as compared to the hollow pipe and abrasive coated tools. The twist drill tool has sharp cutting edges which help in attaining a finer surface finish as compared to the hollow pipe (HP) and the abrasive coated (AC) tools. Abrasive coated (AC) tool shows the hole with burr at the hole edge and irregular hole with hollow pipe (HP) because it does not have any way out for the chips and debris of bone.

A group of researchers have tried to control the temperature rise in drilling of bone using cooling fluids. Kalidindi [13] observed a significant rise in temperature during drilling without coolant. He performed various experiments with external cooling to observe its impact on drilling temperature and found that the external cooling reduces the temperature generated during drilling. Augustin et al. [14] investigated the influence of drill diameter, drill speed and external irrigation (water at $26{ }^{\circ} \mathrm{C}$ ) and concluded that external irrigation is the most important factor for decreasing the temperature. Matthews and Hirsch [15] studied the effect of the use of coolant during drilling of human cortical bone and found that the cooling is highly effective in limiting the maximum temperature elevations. The experimental holes were drilled while being irrigated with water at room temperature at flow rates of 300, 500 and $1000 \mathrm{ml}$ per minute. They showed that higher an increasing of irrigation rate decrease drilling temperature and the temperature never increases beyond $50{ }^{\circ} \mathrm{C}$ for the irrigation rate of $500 \mathrm{ml} / \mathrm{min}$ or above.

Despite of all mechanical damages that can occur during bone drilling, microcracks initiation is the most commonly discussed topic. It is because microcrack initiation during bone drilling has significant impact in implant failure. An increase in the level of these microcracks can decrease the stiffness and elastic modulus of the bone, which may further cause damage to it $[16,17]$. Some of these microcracks could disappear due to bone remodeling [17], but if these microcracks propagate to macro size, may cause fracture to the bone[16,18]. If a length of microcracks is increased significantly this may be the cause of implant failure. O'brien et al [16] studied crack behaviour of cortical bone.
It is showed that microcrack length at the time of osteon encounter is a critical factor in its ability to propagate. If the lengths of microcracks at the time of they encounter cement lines is smaller than approximately $100 \mu \mathrm{m}$, they will stop growing. However, cracks in the range 150-300 $\mu \mathrm{m}$ continued to grow after encountering cement lines but they were unable to penetrate the cement line surrounding secondary osteons and were likely to be deflected around the cement line. These microcracks were often ceased growing soon afterwards. Only microcracks above $300 \mu \mathrm{m}$ in length when they encountered osteons were able to penetrate the cement line. They also concluded that microcracks that occurred in regions of the bone with low osteon density were generally not to cause failure. It is because secondary osteonal bone is mechanically weaker than primary bone [19-21] so failure will be more likely to occur in regions of secondary osteonal bone than in an adjacent region of primary bone. Moreover, Mayya et al.[22] conducted a study to histologically examine the microstructural variations in the cortical bone of mature and young bovine femurs along their length and found that the presence of secondary osteon to be largely confined to the posterior region of any crosssection while the anterior regions are mostly non-Haversian. In addition, the number of secondary osteon is mostly found in mid-diaphysis toward distal end and decreasing toward proximal end, as shown in Figure 1.

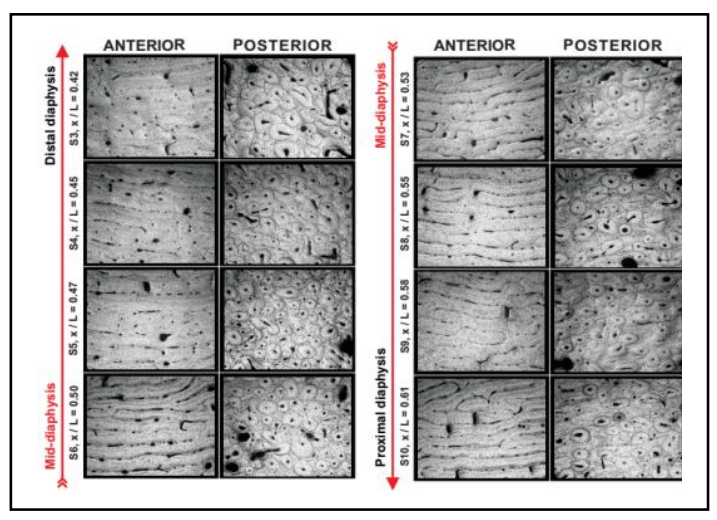

Fig.1 Anatomic variation of microstructures in sections obtained from the mature bovine animal. The field width of micrographs is $1634 \mu \mathrm{m}$. [22]

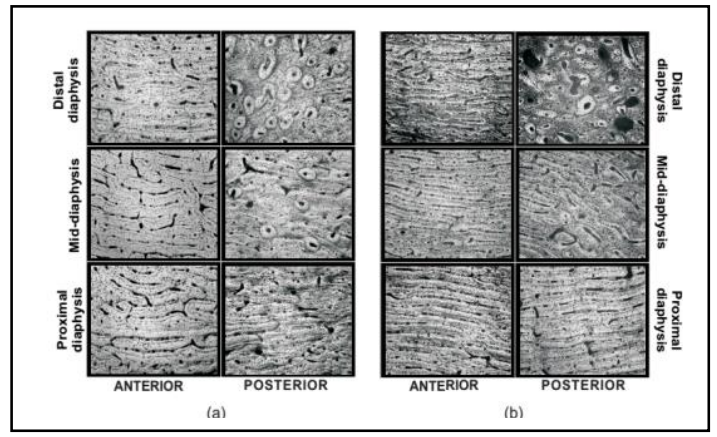

Fig 2. Anatomic variation of microstructures in sections obtained from the femurs of (a) young bovine animal [22] and (b) goat [23] 
This result is similar to the observations in the previous study in goat femur [23]. They also found that the anatomical variations in the microstructure of young (7-8 month in age) bovine femur [see figure 2(a)] is similar to that seen in goat femur (1,5 years in age), as shown in and 2(b). Based on these studies, there may be a correlation between the microstructural variations in the cortical bone and the propagation mechanism of microcrack in cortical bone,which is strongly affected by the presence of osteons.

The main objectives of this study are to understand the effects of coolant on mechanical damages that occur in bone drilling process and to understand the effect of microstructure diffrerence on microcracks that occur in the drilled walls holes. Drilling experiments conducted with cooling fluid as a coolant and using manual hand drill to represent the drilling process in orthopaedic surgery. The result of this study is obtained by analyzing the correlation between microcracks that occurs in bone driling and the microstructural variations in the cortical bone using a number of staining and microscope observation.

\section{Materials ANd Methods}

\subsection{Specimen Preparation}

Experimentation was carried on femurs of mature bovine bones (approx. 2-3 years) and mature goat bones (approx. 1.5-2 years) to represent the difference in anatomical microstructure and osteon density [22,23]. The specimens were obtained immediately after slaughter from a local butcher shop. The specific breed of the animals and whether the animals were of the same breed was not known. No animal was harmed specifically for the experimentation purpose. Then the bone epiphysis were removed using diamond saw and inner bone marrow was squeezed out, just keeping the mid-diaphysis, as shown in Figure 3. A total of four test samples were prepared from two bovine femur bones and two goat femur bones.

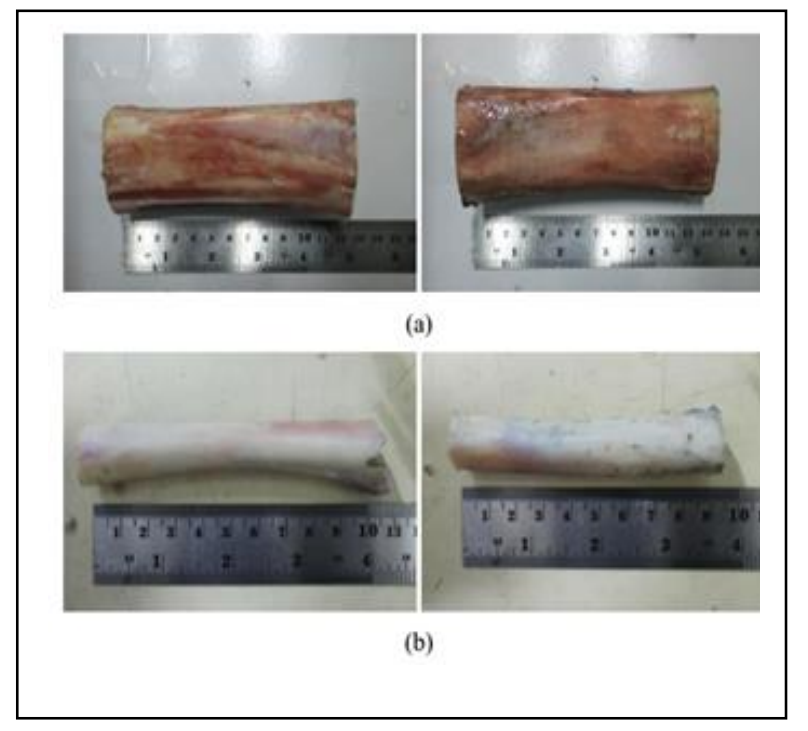

Fig 3. Bone Specimens; (a) Bovine bone; (b) Goat bone
To maintain mechanical properties of bone sample, preservation of bone is needed to keep the specimen hydrated. Fresh bone samples used in this experiment were immersed in $0.9 \%$ saline solution. Then, they were sealed up in a waterproof plastic bag and stored in a refrigerator at -20 ${ }^{\circ} \mathrm{C}$.

Before the experiment, frozen bone samples were unfrozen in room temperature saline solution $\left(25^{\circ} \mathrm{C}\right)$ and then were peeled off from the surface of soft tissues. Water (matrix) accounts for approximately $6 \%$ of the weight and $11 \%$ of the volume of hydrated bone. Thus, changes in water content have a significant effect on mechanical properties of bone [24].

\subsection{Experimental Method}

Drilling experiment was conducted using a manual handdrill. A manual feed was given to drill and the spindle speed was fixed at $1000 \mathrm{rpm}$ to represent the actual manual surgical hand drills speed in orthopaedic surgery $[25,26]$. The drilling speed and feed rate were kept constant throughout the experiments for both bovine and goat bone.The drill was attached to a mechanical arm adapted for vertical movement, providing a constant pressure and precise penetration angle during drilling procedures to prevent the effect of chattering and the slippage of the drill tip during penetration that may cause unnecessary damage to the specimens. Drilling tests were carried out with penetration angle of 0 degree using two-fluted HSS twist drill bit with a diameter of $4 \mathrm{~mm}$ in the presence or absence of external cooling. External cooling was applied to the drill site with a standard $50 \mathrm{ml}$ syringe that contained saline solution at a room temperature of 25 ${ }^{\circ} \mathrm{C}$.

Five consecutive holes from the distal end to the proximal end were generated in each mode on each one of bovine bone and goat bone, as shown in Figure 4. All of the drilling test were conducted at the region that has the highest osteon density, which according to the study of Mayya et al $[21,23]$ was in the posterior region of the bone

Before the drilling tests were conducted, a digital camera was utilized for filming of the chip separation process. The drilling temperature were measured using infrared thermometer that was pointed close to the drill site. The drills were washed and cooled to room temperature after each drilling.

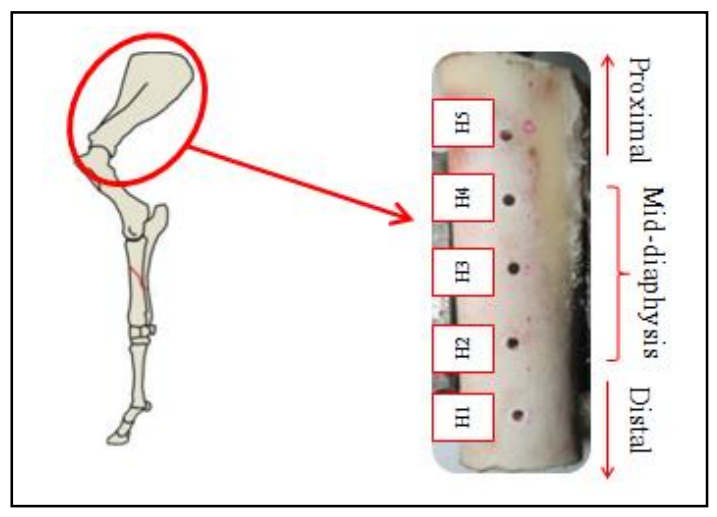

Fig 4. Drilling direction 
The quality of the drilled samples and microcracks that occured on the hole wall surface were examined using Digital Microscope Endoscope (Gizcam 0.3M HD CMOS Sensor) with magnifacation of 1000x. For evaluation of delamination on the drilled hole, the examination was conducted only on the hole surface. For evaluation of burr formation, the examination was conducted on the hole surface and the hole wall surface. Thus, after the examination on the hole surface was conducted, the drilled holes were cut with diamond saw to provide an access to the formed surfaces for evaluation. The drilled hole was cut in transverse direction relative to osteon orientation to analyze the initiation and propagation of crack and their relationship to secondary osteon of the bone specimens. For microcracks evaluation, the drilled holes were stained using methylene blue to label microcracks formed during drilling test. Staining was also used to identify secondary osteon on the wall surface of the hole.

\section{RESULTS AND DISCUSSION}

There is a significant difference in drilling temperature between drilling with coolant and drilling without coolant, as shown in table 1. Drilling of bovine bone without usage of coolant generated mean temperature of $37{ }^{\circ} \mathrm{C}$ while drilling of goat bone without usage of coolant generated mean temperature of $32{ }^{\circ} \mathrm{C}$. It can be concluded that the usage of coolant was very effective in reducing the drilling temperature of $32 \%$ in bovine bone (mean: $25^{\circ} \mathrm{C}$ ) and $22 \%$ in goat bone (mean; $25{ }^{\circ} \mathrm{C}$ ). In addition, there was no measurement exceeded the temperature treshold of thermal necrosis $\left(47^{\circ} \mathrm{C}\right)[1]$.

Table 1 Drilling temperature

\begin{tabular}{|c|c|c|c|c|}
\hline \multirow{2}{*}{$\begin{array}{c}\text { Hole } \\
\text { No. }\end{array}$} & \multicolumn{2}{|c|}{$\begin{array}{c}\text { Drilling without } \\
\text { coolant }\end{array}$} & \multicolumn{2}{|c|}{$\begin{array}{c}\text { Drilling with } \\
\text { coolant }\end{array}$} \\
\cline { 2 - 5 } & $\begin{array}{c}\text { Bovine } \\
\text { bone }\end{array}$ & $\begin{array}{c}\text { Goat } \\
\text { bone }\end{array}$ & $\begin{array}{c}\text { Bovine } \\
\text { bone }\end{array}$ & $\begin{array}{c}\text { Goat } \\
\text { bone }\end{array}$ \\
\hline 1 & $34^{\circ} \mathrm{C}$ & $30^{\circ} \mathrm{C}$ & $25^{\circ} \mathrm{C}$ & $24^{\circ} \mathrm{C}$ \\
\hline 2 & $35^{\circ} \mathrm{C}$ & $31^{\circ} \mathrm{C}$ & $25^{\circ} \mathrm{C}$ & $25^{\circ} \mathrm{C}$ \\
\hline 3 & $40^{\circ} \mathrm{C}$ & $34^{\circ} \mathrm{C}$ & $26^{\circ} \mathrm{C}$ & $24^{\circ} \mathrm{C}$ \\
\hline 4 & $38^{\circ} \mathrm{C}$ & $33^{\circ} \mathrm{C}$ & $25^{\circ} \mathrm{C}$ & $25^{\circ} \mathrm{C}$ \\
\hline 5 & $38^{\circ} \mathrm{C}$ & $33^{\circ} \mathrm{C}$ & $25^{\circ} \mathrm{C}$ & $25^{\circ} \mathrm{C}$ \\
\hline
\end{tabular}

Optical images were recorded at the surface and the wall surface of the hole. From the optical micrograph it was evident that usage of coolant significantly influence the hole quality of the drilled bone. As shown in Figure 5, drilling without coolant in both bovine and goat bone produced noncircular hole with burr-formation and delamination occured in the hole surface.

Burr that occured in bovine bone was higher in height than in goat bone. However it can be seen clearly that hole generated in goat bone has poor quality and rough surface topology.Delamination was found to be bigger in goat bone and bovine bone has a better quality of hole circularity.Moreoever, in hole no. 3 of goat bone, there was a crack initiated and propagated at macro size on the surface of the hole (Figure 6).

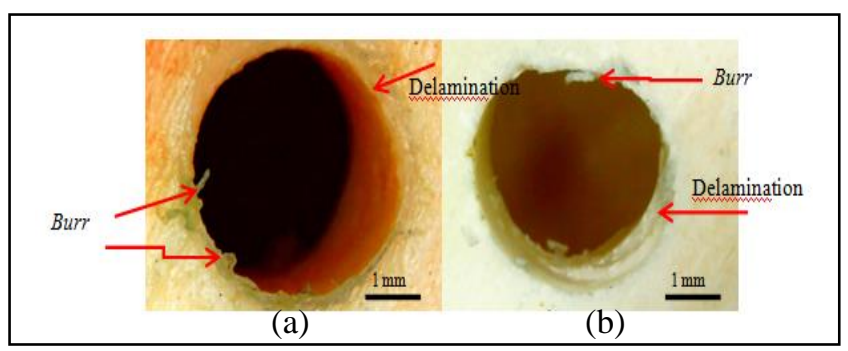

Fig 5. Hole quality of drilling without coolant ; (a) bovine ; (b) goat

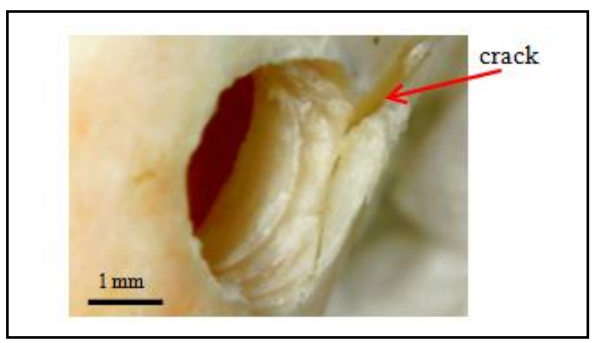

Fig 6. Crack on the hole surface of goat bone.

In addition, optical micrograph of hole wall surface of the drilled bone was obatained and it showed that a lot of damage occured on the inner walls of the holes drilled without usage of coolant, as shown in Figure 7. Large number of burr formation was found on the wall surface of both bovine and goat bone. For several holes in goat bone, there was large tunnel-like groove appeared in the hole wall surface.

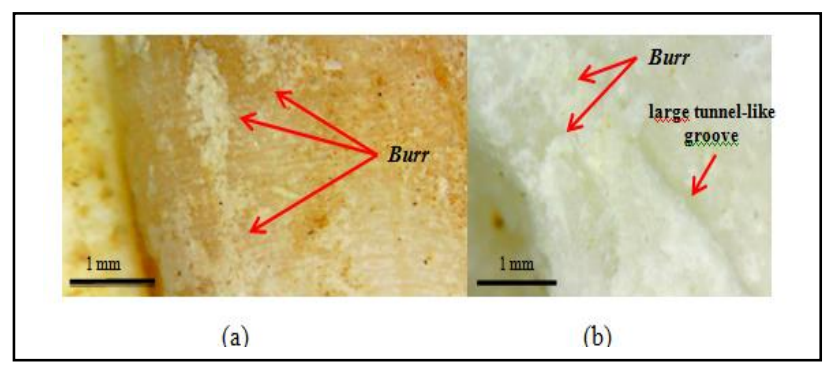

Fig 7. Hole wall surface of ; (a) bovine bone ; (b) goat bone

On the other side, drilling of bone with usage of coolant gives a finer drilled hole with no burr formation or delamination on the surface of the hole, as shown on Figure 8 . Every hole in bovine bone has good quality of circularity with no burr and delamination found. But unlike bovine 
bone, it can still be found a non-circular hole with small amount of burr on some holes of goat bone, (Figure 9).

Optical micrograph of hole wall surface of the drilled bone was obatained and it showed that in case of drilling with coolant, the surface topography of the hole wall has better quality than that drilled without coolant (Figure 10). However, a small amount of burr can still be found near the exit of the drill in hole wall surface.

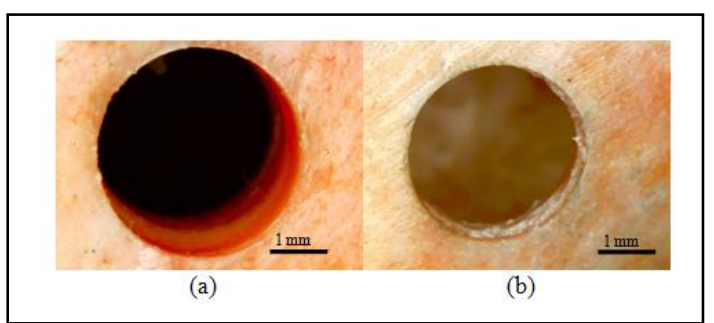

Fig 8. Hole surface of drilling with usage of coolant; (a) bovine bone ; (b) goat bone

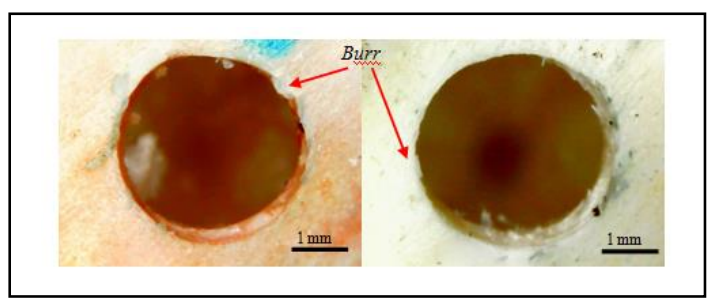

Fig 9. Non-circular holes with burr on goat bone

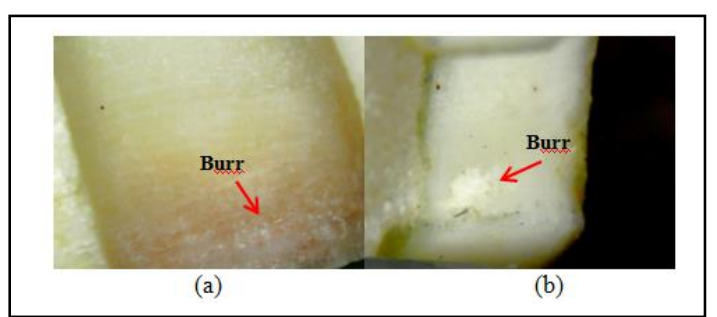

Fig 10. Hole wall surface of; (a) bovine bone; (b) goat bone.

Effects of usage of coolant on initiation of microcracks in the drilled bone were investigated for both bovine and goat bone. In order to investigate microcracks generated on the inner surface of the bone, specimens were stained with methylene blue to label microcracks as methylene blue will easily infiltrate to the crack, allowing an easy differentiation of microcrack and haversian canals visualization. Then the stained speciments were observed with microscope. The effects of usage of coolant on microcrack generation are shown in typical microscopic images as shown in Figures 11-14.

Microcracks were generated in every hole of drilling without coolant for both bovine and goat bone, while in case of drilling with coolant, microcracks were found only on certain holes of goat bone. No microcracks were found in bovine bone that drilled with coolant. It was clearly shown that the usage of coolant affects significantly in the generation of cracks in bone drilling.
As shown in Figures 11-14, each drilling experiment, with same drilling parameters, generated different number and length of microcracks. It can be seen that the length and number of microcrack decreased from $\mathrm{H} 1$ to $\mathrm{H} 5$ for both bovine and goat bone in drilling without coolant. For bovine bone, the longest microcracks was found on $\mathrm{H} 2$ and $\mathrm{H} 3$ whereas for goat bone, the longest microcrack was found on $\mathrm{H} 2$. The highest number of microcracks were generated on $\mathrm{H} 2$ for both bovine and goat bone. In addition, microcracks in bovine bone were found to be longer and higher in number than that in goat bone.

As shown in Figure 4 in this study, drilling tests were conducted in direction from distal end to proximal end of the bone speciments. Study conducted by Mayya et al [22,23] showed that the number of secondary osteon is mostly found in mid-diaphysis toward distal end and decreasing toward proximal end. In other words, the density of secondary osteon was higher on $\mathrm{H} 2$ dan $\mathrm{H} 3$ than any other region of the bone speciment. From a general observation of the specimens, it was hypothesized that the density of secondary osteon may affect the generation of microcrack during drilling.

From this study, it can be concluded that with no surprise, the usage of coolant has significant influence on reducing the drilling temperature. It is due to mechanism of conduction of heat from the drill to the coolant and when coolant exits from the opening at the drill tip, thereby taking away the heat generated during the drilling process.

Meanwhile, it can be seen that usage of coolant also influence the quality of hole in term of burr formation, delamination and microcrack generation during drilling. Besides its function as cooling that taking away the heat generated during driling by conduction, coolant also provides lubrication and irrigation (excluding closed loop internal cooling system)[1]. Lubrication reduces the friction during drilling and hence less heat is generated.

But this still begs the question as to why cracks can still be found in goat bone even though coolant was already applied and suggests that perhaps it was caused by the effect of feed rate and thrust force during drilling of goat bone which was as big as that applied to bovine bone. Whereas in terms of mechanical properties, goat bone is mechanically weaker than bovine bone [27]. To prove this hypothesis, drilling test was conducted to goat bone using the same methods and drilling parameters except the feed rate and thrust force was decrased and drilling penetration was applied slowly. Five consecutive holes were generated from distal end to proximal end for drilling with and without coolant and the results were obtained with the same methods as can be seen in Figures 15 and 16.

Drilling of goat bone without coolant produced noncircular holes and burr formation and delamination were found on the surface and hole wall surface of the bone. Microcracks were found in all of the hole wall surface of the drilled bone. Same as the result obtained on the previous experiment, microcracks were seen to be generated higher in number and length on the distal area of bone speciment.

On the other side, drilling with coolant produced a good quality of hole and no burr or delamination were found. The 
same result obtained on drilling of bovine bone with usage of coolant, the hole wall surface of the drilled bones were seen to have good surface roughness and no microcracks were found as can be seen in Figure 11. Thus it can be concluded that microcracks in drilling of goat bone with usage of coolant were occured due to high feed rate and thrust force that was not compareble with the mechanical strength of the goat bone. Studies conducted by Ndaruhadiet al [8] and Gupta et al [9] supported this conclusion which stated that the increasing of feed rate increase the length and number of microcracks and feed rate was the main parameter that influence the surface topography in bone drilling.

As for the effect of anatomical variation in bone microstructures on microcracks that generated in hole wall surface of the drilled bone, numerous studies have shown that secondary osteonal bone is mechanically weaker than primary bone [19-21]. Study conducted by Carter and Hayes [20] have shown that secondary osteonal bone has lower ultimate tensile strength, stiffness and yield strength compared to primary bone. In other words, due to its high density of secondary osteon, the area of H1-H3 in both bovine and goat bone have lower ultimate tensile strength, stiffness and yield strength than the area of $\mathrm{H} 4$ and $\mathrm{H} 5$. Thus microcracks will be more easily to occur in $\mathrm{H} 1-\mathrm{H} 3$ as it will easily to plastically deformed due to its low yield stregth. In addition, O'brien et al [16] showed that in the event of a microcrack growing to a length which allowed it to penetrate a cement line and eventually reach as far as the Haversian canal in the centre of the osteon, its length and stress intensity were large enough to allow its progression through the osteon and onto the next Haversian system. Thus, once the crack was long enough to break through one Haversian system, it would not be stopped by encounters with either cement lines or Haversian canals and the scenario of cracks propagating from one osteon toanother osteon was consistent with the experimental observations in the study. Mayya et al [22] showed that the number of secondary osteons in the posterior region increases towards the middiaphysis with the microstructure having secondary osteons that are closely packed and in few cases overlapping each other. Therefore, once microcracks were able to penetrate the cement line or even propagate and splitting the haversian canals, crack would easily found another osteon and propagate even bigger due to that closely packed osteon in mid-diaphysis and distal end area. This could be the reason why several cracks were found to propagate splitting a number of osteon in area of $\mathrm{H} 2$ and $\mathrm{H} 3$ of both bovine and goat bone. So it can be concluded that microstructure of cortical bone have a big influence on initiation and propagation of microcrack during bone drilling.
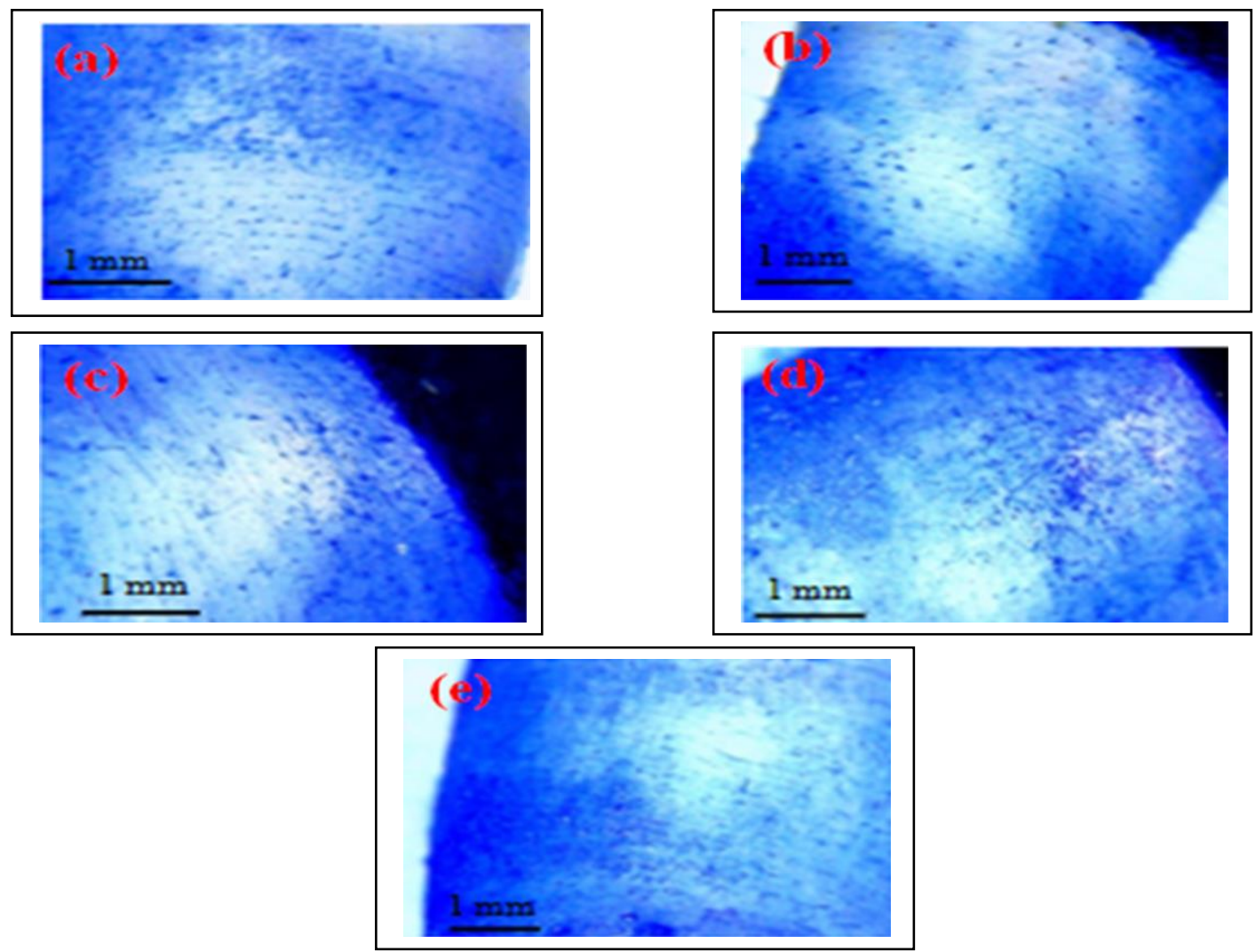

Fig 11. Microscopic image of drilling of bovine bone with coolant; (a) hole no. 1; (b) hole no. 2; (c) hole no. 3 ; (d) hole no. 4 ; (e) hole no. 5 

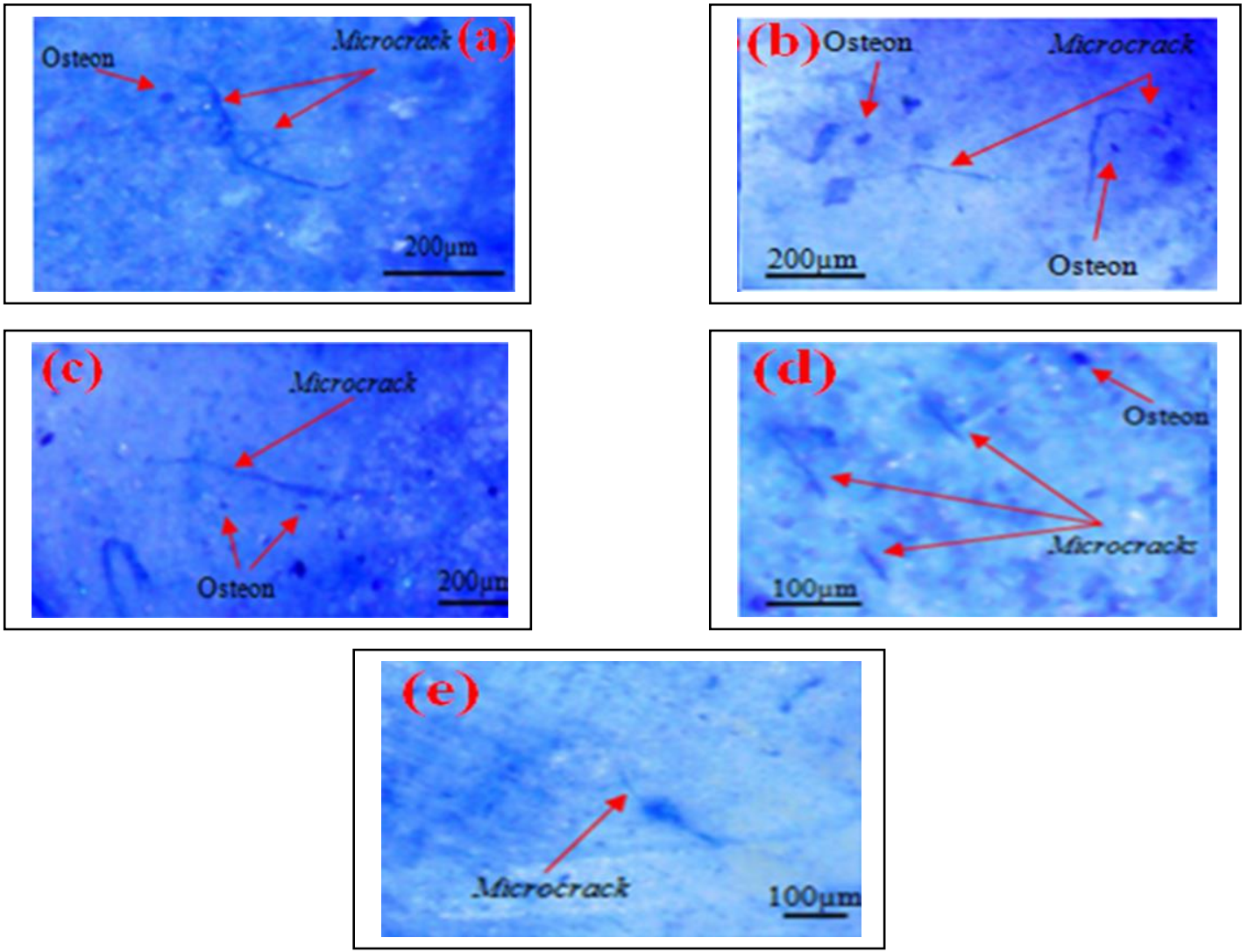

Fig 12. Microscopic image of drilling of bovine bone without coolant; (a) hole no. 1; (b) hole no. 2; (c) hole no. 3; (d) hole no. 4; (e) hole no. 5
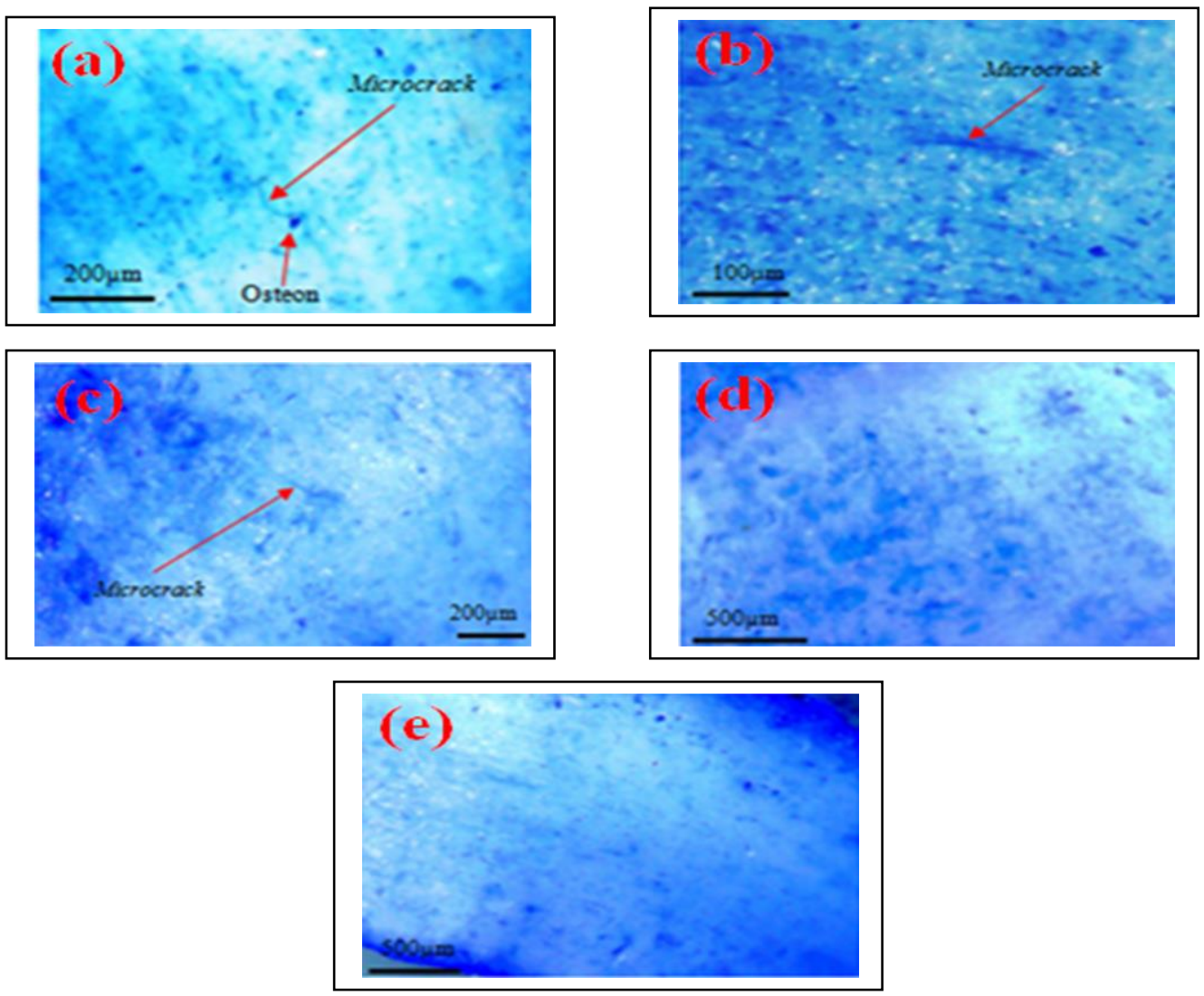

Fig 13. Microscopic image of drilling of goat bone with coolant; (a) hole no. 1; (b) hole no. 2; (c) hole no. 3; (d) hole no. 4; (e) hole no. 5 

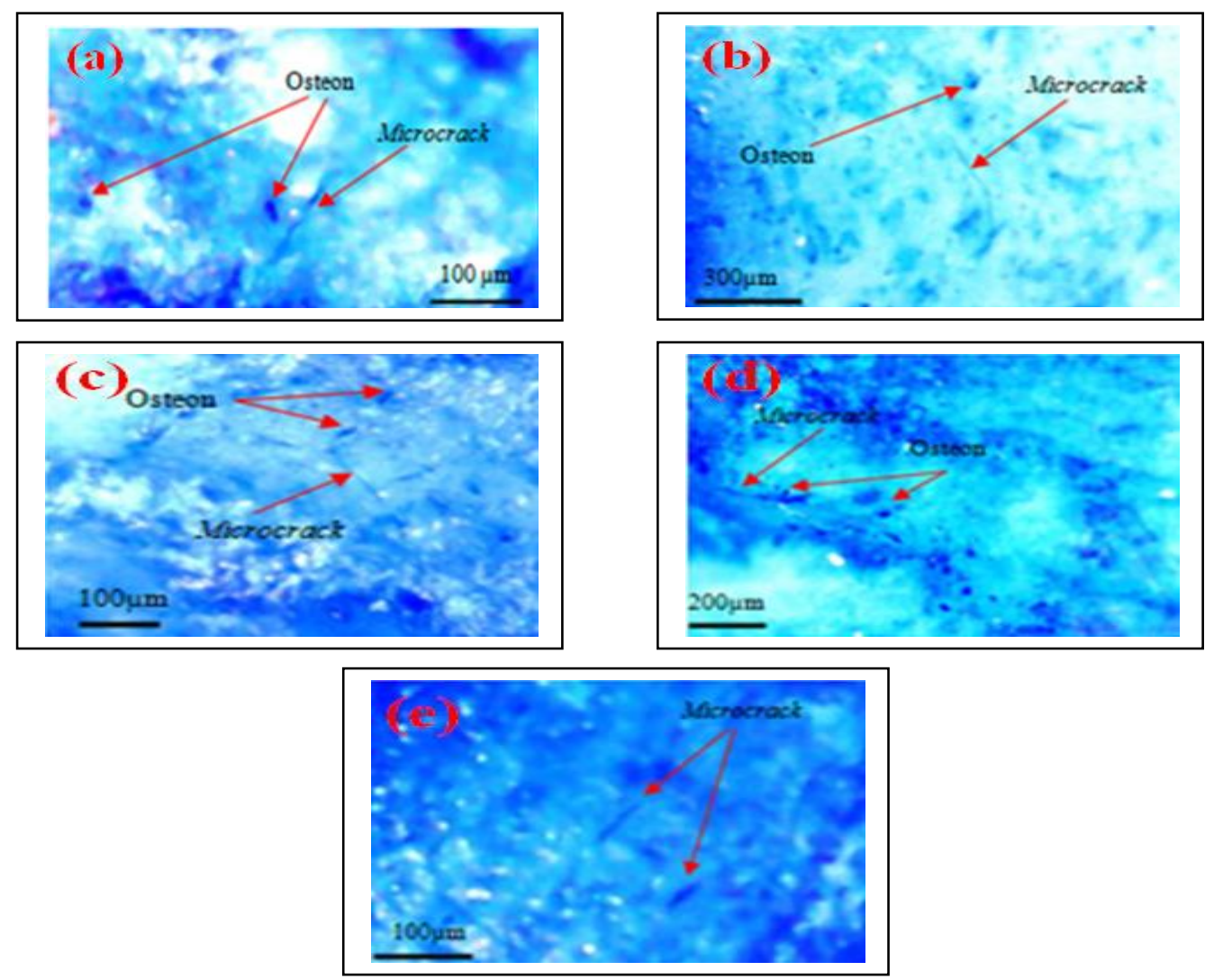

Fig 14. Microscopic image of drilling of goat bone without coolant; (a) hole no. 1; (b) hole no. 2; (c) hole no. 3; (d) hole no. 4; (e) hole no. 5
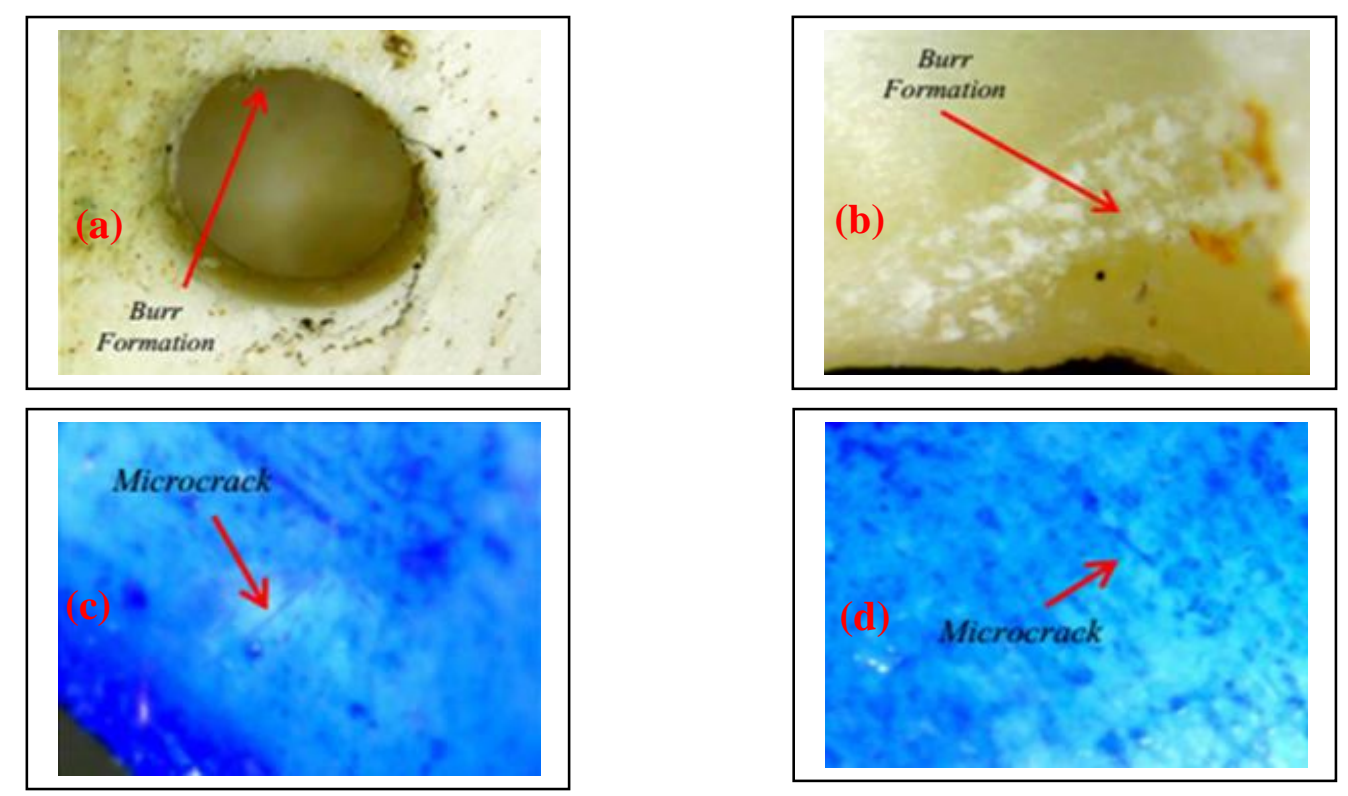

Fig 15. Microscopic images of drilling of goat bone without coolant; (a) \& (b) burr formation; (c) \& (d) microcracks on wall surface of the hole 

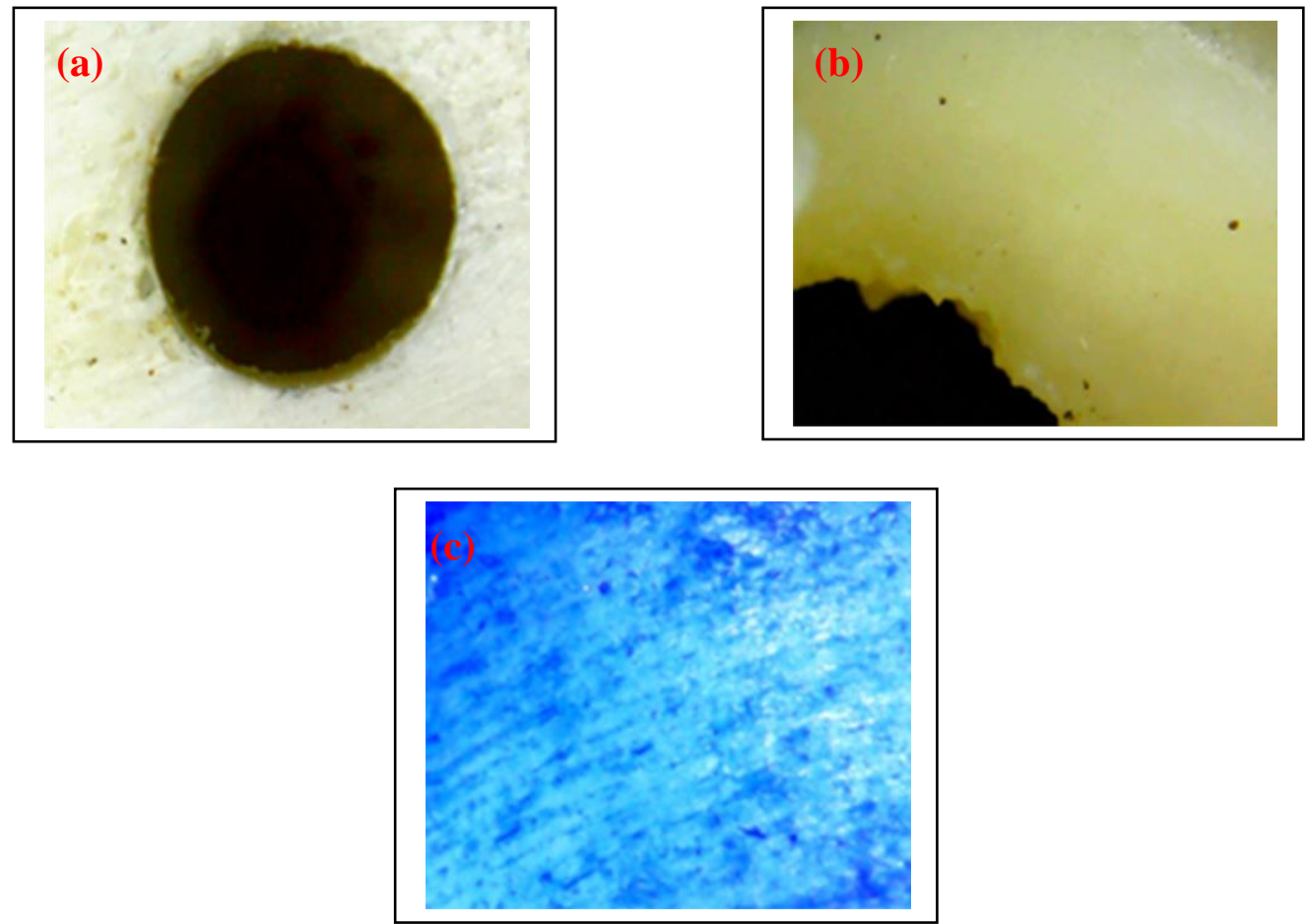

Fig 16. Microscopic images of drilling of goat bone with coolant; (a) \& (b) no burr formation; (c) no microcracks on wall surface of the hole

\section{CONClusion}

The findings obtained in this study confirmed that usage of coolant significantly influence the heat generated in bone drilling. In addition, drilling with coolant generated less damage (burr, delamination, microcracks) on surface and wall surface of the drilled hole. No microcracks and delamination were found in the surface and wall surface of the drilled hole using coolant, although a small amount of burr can still be found on the wall surface due to drill cloging of sticky paste of the chips. Another advantage of usage of coolant is improvement in chip removal from the drilling site. The function of lubrication and irrigation of coolant can reduce the contact between the drill, chips and bone, thus produce lower heat since it diminishes chip rubbing against the drill hole leading to reduced friction and less damage to the bone.

The obtained results also showed that there was a strong correlation between the initiation of microcracks and the anatomical variation of microstructure in cortical bone. The number and length of microcracks in bovine bone was higher than that in goat bone. Moreover, it was also found that the number and length of microcracks was increasing from proximal to mid-diaphysis and distal area of bone. It was due to the difference in mechanical properties along the bone that depends on osteon density along the cortical bone.

\section{REFERENCES}

[1] R. K. Pandey, S. S. Panda, "Drilling of bone: A comprehensive review," Journal Of Clinical Orthopaedics and Trauma, 2013, 4 (1), pp. $15-30$
[2] G. Singh, "Optimization of process parameters for drilled hole quality characteristics during cortical bone drilling using Taguchi method," Journal of the Mechanical Behavior of Biomedical Materials, 2016, vol. 62, pp. $355-365$.

[3] E. Shakouri, H. H. Hassanalideh, S. Gholampour S, "Experimental investigation of temperature rise in bone drilling with cooling: A comparison between modes of without cooling, internal gas cooling, and external liquid cooling," Proceedings of the Institution of Mechanical Engineers, Part H: Journal of Engineering in Medicine, 2017, pp. 1-9.

[4] G. F Maria, M. F. Elza, N. J. Renato, "Assessment of different drill diameter on bone drilling,", Journal of Mechanical Engineering and Biomechanics, 2017, vol. 1, issue 6, pp. 135-141.

[5] X. Li, W. Weibin, W. Wenwang, Q. Zhaoliang, T. Ran, K. Angelo, L. Binbin, L. Ying, F. Daining, "Mechanical response of cortical bone in compression and tension at the mineralized fabrillar level in stereoid induced osteoporosis," Composites Part B, 2020, 196, 108138, pp. 1-11.

[6] A. Foli, L. C. Gael, B. Anne-Sophie, M. Abdelhadi, "An analytical modeling with experimental validation of bone temperature rise in drilling process, Medical Engineering and Physics, 2020, 84, pp. 151-160.

[7] B. Xiaopan, H. Shujun, L. Kai, Q. Yunxia, Z. Weidong, "Analysis of machining process and thermal condition during vibrationassisted cortical bone drilling based on generated bone chip morphologies," Medical Engineering and Physics, 2020. 83, pp. 73-81.

[8] M. W. Ndaruhadi, S. Sharif, D. Kurniawan, "Effect of different cutting speed and feed rate on surface roughness in femur bone drilling," Procedia Manufacturing. 2015, vol. 2, pp. 208-211.

[9] V. Gupta, P. M. Pandey, V. V. Silberschmidt, "Rotary ultrasonic bone drilling: improved pullout strength and reduced damage," Medical Engineering and Physics, 2017, vol. 41, pp. 1-

[10] K. Alam, S. Z. Qamar, "Ultrasonically assisted bone drilling effect of process parameters on delamination," Materials and Manufacturing Processes, 2018, vol. 33, issue 16, pp. 1-5.

[11] G. Singh, A. Babbar, V. Jain, D. Gupta, "Comparative statement for diametric delamination in drilling of cortical bone with conventional and ultrasonic assisted drilling techniques,” Journal 
of Orthopaedics, 2021, doi https://doi.org/10.1016/j.jor.2021.03.017

[12] R. K. Pandey, S. S. Panda, "Evaluation of delamination in drilling of bone," Medical Engineering and Physics, 2015, vol. 37, pp. $657-664$.

[13] V. Kalidindi, "Optimization of drill design and coolant systems during dental implant surgery," MS thesis, University of Kentucky, USA, 2004

[14] G. Augustin, S. Davila, T. Udilljak, T. Staroveski, D. Brezak, S. Babic, "Temperature changes during cortical bone drillingwith a newly designed step drill and internally cooled drill," International Orthopaedics, 2012, 36, pp. 1449-1456.

[15] L. S. Matthews, C. Hirsch, "Temperatures measured in human cortical bone when drilling," Journal of Bone Joint SurgeryAmerican, 1972, 54 (2), pp. 297-308.

[16] J. O'brien, D. Taylor, T. Lee, "The effect of bone microstructure on the initiation and growth of microcracks," Journal of Orthopaedic Research, 2005, 23, pp. 475-480.

[17] D. Taylor, J. H. Kuiper, "The prediction of stress fractures using a 'stressed volume' concept," Journal of Orthopaedic Research, 2001, 19(5), pp. 919-926.

[18] F. J. O'Brien, D. Taylor, T. C. Lee, "Microcrack accumulation at different intervals during fatigue testing of compact bone," Journals of Biomechanics, 2003, vol. 36, pp. 973-80

[19] D. R. Carter, W. C. Hayes, "Compact bone fatigue damage: microscopic examination," Clinical Orthopaedic \& Releated Research, 1977, pp. 127:26-74.

[20] D. R. Carter, W. C. Hayes, "Compact bone fatigue damageResidual strength and stiffness, "Journal of Biomechanics, 1977, 10 (54), pp. 325-337.
[21] S. Saha, W. C. Hayes, "Relations between tensile impact properties and microstructure of compact bone," Calcified Tissue Research, 1977, 24 (1), pp 65-72.

[22] A. Mayya, A. Banerjee, R. Rajesh, "Haversian microstructure in bovine femoral cortices: An adaptation for improved compressive strength," Materials Science and Engineering C: Materials for Biological Applications, 2015, 59, pp. 454-463.

[23] A. Mayya, A. Banerjee, R. Rajesh, "Mammalian cortical bone in tension is Non-Haversian," Scientific Reports, 2013, vol 3, 2533, pp. 1-6.

[24] H. Yuehuei, R. A. Draughn, "Mechanical testing of bone and the bone-implant interface, New York: CRC Press, 1999.

[25] M. S. Noorazizi, R. Izamshah, M. S. Kasim, "Effects of drill geometry and penetration angle on temperature and holes surfaces for cortical bovine bone: An in vitro study," Procedia Engineering, 2017, 184, pp. $70-77$.

[26] C. W. Höller, "Technical and economic analysis of the process of surgical bone drilling and improvement potentials". MS Thesis. Mechanical Engineering and Business Economics, Graz University of Technology, Austria, 2015.

[27] H. Duan, Y. Hongsheng, X. Yan, Z. Bin, R. Chen, M. Li, Z. Wenli, Y. Yonggang, L. Hong, P. Fuxing, T. Chongqi, "Effects of mechanical loading on the degradability and mechanical properties of the nano calcium deficient hydroxyapatite-multi (amino acid) copolymer composite membrane tube for guided bone regeneration, International Journal of Nanomedicine, 2013, 8, pp. 2801-2807

(C) 2020. This article is an open access article distributed under the terms and conditions of the Creative Commons Attribution (CC BY) license (http://creativecommons.org/licenses/by/4.0/) 